\title{
External Dacryocystorhinostomy and Patient Satisfaction: Perspective of General Ophthalmologist
}

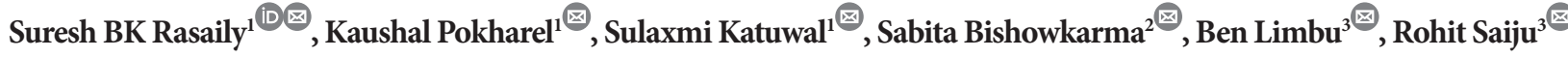 \\ ${ }^{1}$ Rapti Eye Hospital, Nepal \\ ${ }^{2}$ Tribhuwan University Teaching Hospital, Kathmandu, Nepal \\ ${ }^{3}$ Tilganga Institute of Ophthalmology, Kathmandu, Nepal
}

\begin{abstract}
Introduction: This study aimed to evaluate patient satisfaction over time in patients undergoing external dacryocystorhinostomy for primary nasolacrimal duct obstruction when done by a general ophthalmologist.

Materials and methods: This prospective interventional case series was done in a secondary level eye hospital in the Midwestern region of Nepal from 1st January 2018 to 30th December 2018. Fifty-four consecutive adult patients diagnosed with primary nasolacrimal duct obstruction who underwent external dacryocystorhinostomy performed by a general ophthalmologist were included. The surgical success rate was determined at six months on the basis of the resolution of symptoms with patency on syringing. Postoperative patient satisfaction was evaluated 6 months after surgery with a standardized Glasgow Benefit Inventory and post-intervention questionnaire.

Results: A total of 54 eyes were operated on within the study period and a larger number of surgeries were done in the age group 26-30 years. Female constituted $79.6 \%$ and male $20.4 \%$ with a ratio of 3.9:1. Overall surgical success rate 6 months after surgery was $96.30 \%$. The mean total Glasgow benefit inventory (GBI) score was $48.83 \pm 23.87$ (95\% CI, 42.96- 56.95), mean general subscale score was $52.70 \pm 23.28$ (95\% CI, 46.49-60.38), social support subscale was $49.69 \pm 44.68$ (95\% CI, 41.15-60.35) and physical health subscale score was $37.07 \pm 41.19$ (95\% CI, 27.48-49.26).

Conclusion: The external dacryocystorhinostomy surgeries performed by general ophthalmologists achieved an excellent surgical success rate and good patient satisfaction proven by a validated questionnaire.

Key words: External Dacryocystorhinostomy, General ophthalmologist, Glasgow Benefit Inventory, Patient satisfaction, Surgical success.
\end{abstract}

Financial Interest : Nil

Conflict of Interest : Nil

Corresponding Author

Dr. Suresh BK Rasaily

Rapti Eye Hospital, Dang, Nepal

E-mail: srasaly@gmail.com

Contact: +9779857824998
Received : 15.10.2020

Accepted : 01.04.2021
Access this article online

Website: www.nepjol.info/index.php/NEPJOPH

DOI: https://doi.org/10.3126/nepjoph.v13i2.31701

Copyright $\odot 2021$ Nepal Ophthalmic Society

ISSN: 2072-6805, E-ISSN: 2091-0320

This work is licensed under a Creative Commons

Attribution-NonCommercial-NoDerivatives 4.0 International License (CC BY-NC-ND). 


\section{INTRODUCTION}

Watering in the eye is due to hypersecretion or reduced tear outflow because of relative or absolute obstruction of the lacrimal system. The persistent watering is socially embarrassing because it looks like persistent crying. The persistent watering impacts on quality of life by blurring vision, spattering glasses, and leading to skin soreness (Feretis et al, 2009; Fayers et al, 2009).

The external dacryocystorhinostomy (Ex-DCR) surgery was first introduced by Toti in 1904 and further refined in 1920 by Dupuy-Dutemps and Bourget. It has remained the gold standard in the management of epiphora for its high success rate, rapid primary intention healing due to the suturing of mucosal flaps, and low equipment costs (Hartikainen et al,1998). External DCR is a bypass surgery forming an anastomosis between the tear sac and nasal mucosa, thereby allowing tears to empty directly from the tear sac into the cavity (Mohammad et al,2018).

The GBI questionnaire was first developed and used by Robinson in otolaryngological (ORL) procedures (Robinson et al,1996). It is a validated post-interventional questionnaire sensitive to change in health status after surgical procedures. It contains 18 questions, each of which is based on a five-point Likert scale (Karim et al, 2011; Jutley et al,2013). The questions are specifically designed to measure the general perception of well-being (12 questions), Social parameters (3 questions), and Physical health parameters (3 questions).
The total GBI score ranges from -100 (extreme negative benefit), through zero (no change) to 100 (extreme positive benefit in health status). However, a positive score represents patient satisfaction with the surgical intervention.

In the context of Nepal, the prevalence of nasolacrimal duct obstruction is more common in sub-tropical lowlands as compared to high hills (Badhu et al,2005). Most eye hospitals located in the Terai region, have high volume cataract surgery and external dacryocystorhinostomy is usually performed by general ophthalmologists with surgical skill but without valid either short term or long term subspecialty training. However, the quality of life after Ex-DCR performed by general ophthalmologists is not well studied. So this study aimed to evaluate patient satisfaction and quality of life after external dacryocystorhinostomy performed by ophthalmologists who do not have subspecialty training in orbital plastic and lacrimal surgery.

\section{MATERIALS AND METHODS}

This prospective interventional case series was conducted in a secondary level eye hospital located in the Midwestern region of Nepal from January 2018 to December 2018 in accordance with the tenets of the Declaration of Helsinki. Ethical approval was obtained from the hospital management board and well-informed written consent was taken from participants.

All consecutive patients undergoing ExDCR who consented to participate in the study were included while patients with 
failed DCR, secondary acquired nasolacrimal duct obstruction, and those with punctual anomalies, canalicular/common canalicular obstruction were excluded. Data based on demographic profile, complete ocular, and systemic examination, DCR with or without a stent, intra-operative and postoperative complications, interpretation of lacrimal irrigation on subsequent follow-up visits were collected in customized Proforma. All the eligible patients were well explained about the surgery, possible complications, advantages, and disadvantages of Silastic tube intubation, and the extra cost of the stent. The choice of the type of surgery (DCR only or DCR with tubing) was based on the patient's preferences. Each patient was advised for routine baseline blood investigation like complete blood count, blood sugar, bleeding and clotting time, serological test to rule out HIV, Hepatitis B, and C.

All the surgeries were done by a single surgeon (The author) under aseptic precaution. Pre-operatively, intramuscular injection of Diclofenac sodium $(1.5 \mathrm{mg} / \mathrm{kg})$ was given in the buttock 30 minutes before surgery. After prepping and draping, local anesthetic agents (2\% Lidocaine with Adrenaline 1: 100,000 + $0.5 \%$ Bupivacaine) were infiltrated to block infraorbital, infratrochlear, dorsal nasal, and anterior ethmoidal nerves. Nasal mucosa was decongested with gauge ribbon soaked in $4 \%$ Lidocaine with Adrenaline 1:100,000 and Oxymetazoline $0.05 \%$. A curvilinear incision of about $10-12 \mathrm{~mm}$ in length was given with the number 15 Bard-Parker surgical blade along the anterior lacrimal crest. The orbicularis muscle was bluntly dissected to reach the periosteum. Lacrimal sac fossa was exposed by separating the periosteum from bone and reflecting laterally. Bone punching was started at the junction of lamina papyracea of the ethmoid and lacrimal bone and an approximately $1.5 \mathrm{~cm} \times 1.5 \mathrm{~cm}$ bony ostium created with Kerrison rongeur. The lacrimal sac was incised postero-inferiorly in an H-shaped fashion to open it like a book. A similar H-shaped incision was made at the nasal mucosa. The posterior flap of the lacrimal sac was sutured with a posterior nasal flap with Vicryl 6-0. Bicanalicular Silastic tube intubation was done for those who preferred to pay the extra cost of the tube. Subsequently, anterior flap reconstruction (with anterior nasal and anterior lacrimal flap) was done using Vicryl 6-0 suture. Finally, the Orbicularis muscle and skin were closed with 6-0 Vicryl sutures. Postoperative nasal packing is done with gauze soaked in 4\% Lidocaine with Adrenaline 1:100,000 and Oxymetazoline $0.05 \%$. Antibiotic ointment was applied and wound patched with a cotton gauge.

After surgery, each patient was prescribed oral antibiotics, analgesics, proteolytic enzymes, and postoperative instructions were given. After overnight observation, the nasal pack was gently removed, the wound cleaned with $5 \%$ betadine, topical antibiotics, steroid and nasal decongestants were prescribed. After 1 week of surgery, all the sutures were removed and topical antibiotics drops were continued for 1 month. The tube was removed after 3 months of surgery as per protocol implemented in our 
hospital. Lacrimal syringing was performed in each case and an interview based on the standardized questionnaire was taken 6 months after surgery. After 6 months of surgery, resolution of symptoms with patency on irrigation was considered as surgical success whereas no symptomatic improvement in symptoms and/or inability to irrigate lacrimal system was considered a failure.

Data entered into Microsoft Excel 2016 and statistically analyzed using Statistical Package for the Social Sciences (SPSS version 20, IBM, USA). P-value $<0.05$ was considered statistically significant. All the responded questionnaires were analyzed providing total, general subscale, social, and physical scores. The total GBI score was calculated by summing all the responses (Qu. 1-18), dividing by 18 (to obtain an average response score) then subtracting 3 from the average response score and multiplying by 50. Similarly, the general subscale score was calculated by summing 12 responses (Qu. $1,2,3,4,5,6,9,10,14,16,17$ and 18) dividing by 12 (to obtain an average response score) then subtracting 3 from the average response score and multiplying by 50 . Likewise, the social support score was calculated by summing 3 of the responses (Qu. 7,11,15), dividing by 3(to obtain an average response score) then subtracting 3 from the average response score and multiplying by 50 .

\section{RESULTS}

Fifty-four adult patients with primary nasolacrimal duct obstruction were eligible. Of the total, 43(79.6\%) were female and 11 $(20.4 \%)$ male with a ratio of $3.9: 1$. A large number of surgeries were performed in the age group 26-30 years (29.6\%) and followed by the age group $31-35$ years $(20.4 \%)$. Out of the total, 36(66.7\%) eyes were intubated with bi-canalicular silastic tube whereas 18 (33.3\%) eyes were not intubated.

In this study, 52(96.3\%) patients achieved surgical success after 6 months of surgery. The overall rate of surgical success and failure are as shown in Table 1.

The presenting study showed that the mean total GBI score was $48.83 \pm 23.87$ (95\% CI 42.96$56.95)$, mean general subscale score was $52.70 \pm$ 23.28 (95\% CI, 46.49-60.38). The mean social support subscale score and physical health subscale score are as shown in Table 2.

Table 1: Surgical outcome after 6 months of surgery.

\begin{tabular}{|l|c|c|}
\hline \multicolumn{1}{|c|}{ Surgical outcome } & Number & \% \\
\hline Surgical success & 52 & 96.30 \\
\hline Surgical failure & 2 & 3.70 \\
\hline Total & 54 & 100 \\
\hline
\end{tabular}


Table 2: Glasgow Benefit Inventory scoring.

\begin{tabular}{|l|c|c|}
\hline \multicolumn{1}{|c|}{ GBI } & Mean (SD) & 95\% CI ( Range ) \\
\hline Total GBI score & $48.83(23.87)$ & $42.96-56.95$ \\
\hline General sub- health score & $52.70 \pm 23.28$ & $46.49-60.38$ \\
\hline Social support score & $49.69 \pm 44.68$ & $41.15-60.35$ \\
\hline Physical health score & $37.07 \pm 41.19$ & $27.48-49.26$ \\
\hline
\end{tabular}

The current study revealed that the age group 36-40 years has the highest mean total GBI score 61.11(SD 24.05), general sub-health 60.71(SD 25.90), and physical health 66.67(SD 47.17) whereas the highest mean social support score was present in the age group 45-50 year. Likewise, the lowest mean total GBI score 29.17(SD 13.75), and a general sub-health score of 29.16(SD 17.68) were found in the age group 51-55 years. However, the lowest mean social support score was found in the age group 61-55 years and the lowest physical health score was found in the age group above 51year. Figure 1 depicts the mean GBI scores distribution by age group.

Two patients who complained of persistent epiphora and had regurgitation from opposite punctum on syringing after six months of surgery were considered as failed cases. However, the failed DCR cases underwent revision DCR surgery through the same incision to enlarge the ostium with bi-canalicular Silastic intubation

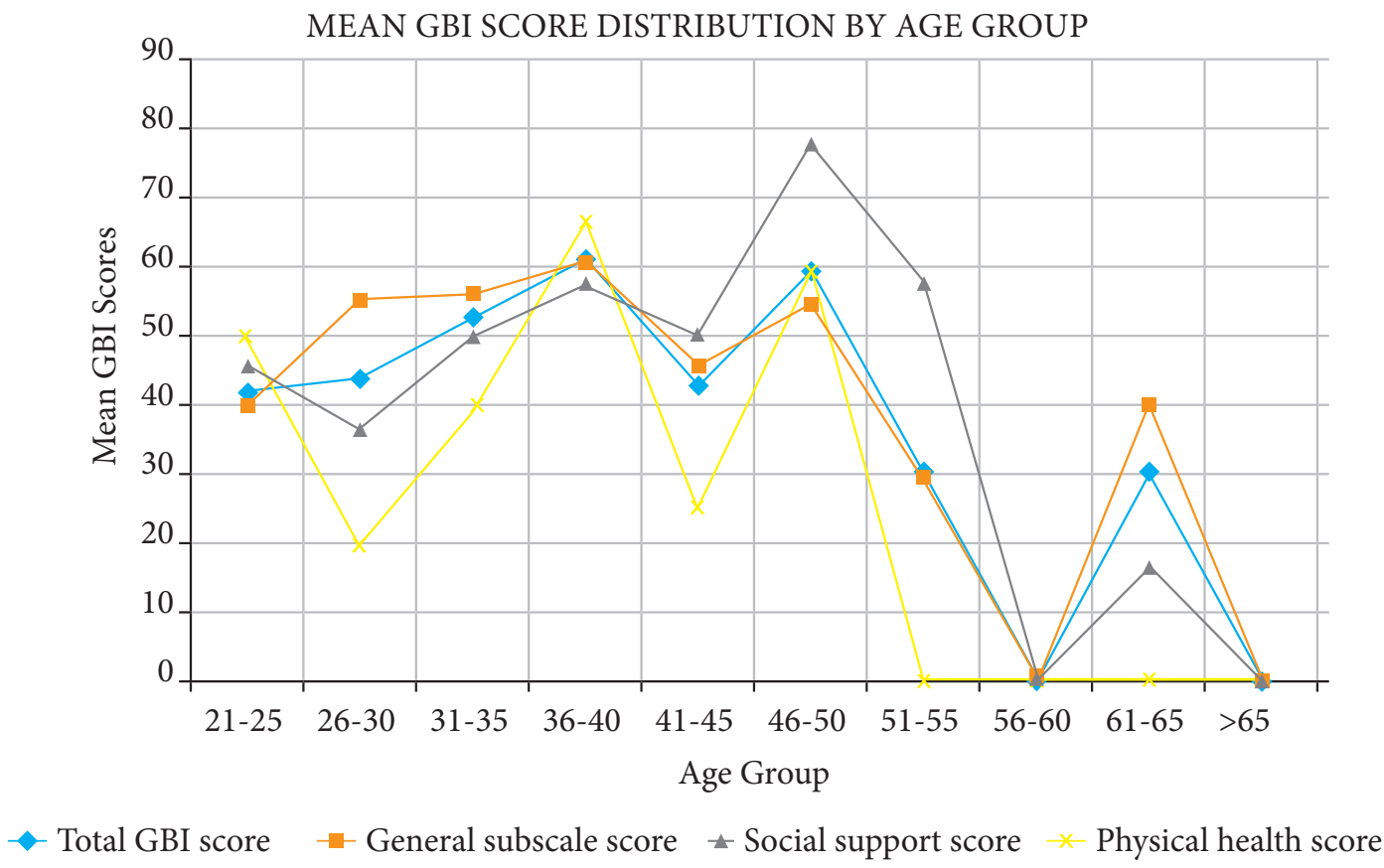

Figure 1: Mean GBI scores distribution by age group. 
by the same surgeon. Epiphora was completely resolved in both cases at 3 months after revision DCR and the tube was removed. At 6 months' follow-up visit both cases were free of symptoms and patent on irrigation.

\section{DISCUSSION}

In this study, the majority of patients undergoing external dacryocystorhinostomy were in the age group 26-30 years $(29.6 \%)$ followed by 31-35 years $(20.4 \%)$. The primary acquired nasolacrimal duct obstruction is common in the middle age group and the elderly age group. However, old people prefer not to undergo surgery due to the fact that the amount of lacrimal secretion is less. Nasolacrimal duct obstruction was more common in the $3 \mathrm{rd}$ and 4th decades of life reported in the published literature (Mortimore et al, 1999 and Moras et al, 2011) which is consistent with our study.

In our study, 43(79.6\%) patients were female and $11(20.4 \%)$ male with a ratio of $3.9: 1$ which is similar to female predominance of $46(76.7 \%)$ and male $14(23.3 \%)$ with a ratio of 3.2:1 in the study (Duwal et al., 2015). The female predominance in our study is due to a higher incidence of acquired nasolacrimal duct obstruction owing to anatomical narrowing of the bony lacrimal canal in females more than males. Two-thirds of total patients preferred bicanalicular Silastic tube intubation while onethird patients preferred surgery without stent. The possible reason behind not keeping a stent could be an additional cost of a silastic tube. However, there are some authors who believe that silicon tube will prevent failure of DCR
(Hurwitz et al., 1986), whereas others thought that stenting cause granulomatous inflammation and DCR stenosis with low success rate and complications as punctal erosion and slitting of canaliculi (Sham et al., 2000). In a comparative prospective study of external DCR with or without silastic intubation, success rates of 90 $\%$ (with Silastic intubation) and $87 \%$ (without Silastic intubation) were found (Saiju et al, 2009).

The presenting study reported cheese wiring of lower punctum in $1(1.85 \%)$ eye in which tube was removed earlier. The cheese wiring in our study is lower than $7.9 \%$ reported in a study by Sharma BR (2008). The Silastic tube was removed after 3 months of surgery as per the protocol that we follow in our center. The reason behind keeping the silastic tube for 3 months in our study is the learning curve of a general ophthalmologist. However, a randomized controlled trial (Limbu et al., 2019), reported no significant difference in early tube removal (2 weeks) versus standard tube removal (6 weeks).

In another study, the surgical outcome and patient satisfaction were evaluated in each case 6 months after surgery (Fayers et al, 2009). Out of the total, $52(96.3 \%)$ patients were free of watering and had patency on syringing whereas $2(3.70 \%)$ patients reported still watering and regurgitation on syringing from the opposite punctum. The overall surgical success rate in our study (96.3\%) was similar to that reported in other studies: $95 \%$ by Goel et al. (2016), $94.54 \%$ by Dasgupta et al. (2016) and $94.1 \%$. by Duwal et al. (2015). 
We aimed to analyze patient's satisfaction using the Glasgow Benefit Inventory (GBI) questionnaire and found that the mean total score from the GBI was $48.83 \pm 23.87$ (95\% CI 42.96- 56.95), mean general subscale score was $52.70 \pm 23.28$ (95\% CI, 46.49-60.38), social support subscale was $49.69 \pm 44.68(95 \% \mathrm{CI}$, 41.15-60.35), physical health subscale score was $37.07 \pm 41.19(95 \%$ CI, 27.48-49.26) suggesting that external DCR performed by a general ophthalmologist can achieve good patient satisfaction. However other studies analyzed the mean GBI scores of +16.1 (Hii et al., 2012) and 18.7 (Feretis et al., 2009) which are inconsistent with our study. Most of the patients after 6 months of surgery tend to give good responses irrespective of anatomical patency as they are free of symptoms or improved. In the earlier postoperative period, patients may not respond well despite patent lacrimal passage. However, Tarbet and Custer et al. (1995) and Delaney and Khooshabeh et al., 2002) studies showed that only $62 \%$ of patients reported to suffer with persistent epiphora despite a patent syringing.

In the present study, the adult age group 36-40 years has the highest mean GBI score in total $61.11 \pm 24.05$, general sub-health $60.71 \pm 25.90$, and physical health $66.67 \pm 47.17$ whereas highest mean social support in the age group 45-50 year whereas the lowest mean total GBI score $29.17 \pm 13.75$ and general sub-health score $29.16 \pm 17.68$ were found in the age group 51-55 years. There was no change in physical health score in the age group above 50 years. The younger adult patients had improved general perception of well-being compared with older patients.

\section{CONCLUSION}

This prospective interventional case series showed that NLDO is more common in the age group 26-35 years with female predominance $79.6 \%$ and male: female ratio of 1:3.9. Overall surgical outcome and patient satisfaction after external DCR performed by a general Ophthalmologists in the secondary level hospitals were good and comparable to that performed by an oculoplastic surgeon. This study aims to support continuing external DCR as a routine surgical procedure in the secondary level hospital where the oculoplastic surgeon is not available.

\section{Limitation}

The study was nonrandomized and with a relatively small sample size. We were obliged to follow our own hospital's protocol for silastic tube intubation and removal rather than the standard protocol followed in other tertiary centers.

\section{Acknowledgment}

We would like to acknowledge Ms. Sapana Gautam and Ms. Nisha Bishowkarma for data collection and entry for this particular study. 


\section{REFERENCES}

Ali MJ ed. (2018). Principles and practice of lacrimal surgery. Springer.

Badhu B, Dulal S, Kumar S, Thakur SKD, Sood A, Das H (2005). Epidemiology of Chronic Dacryocystitis and Success Rate of External Dacryocystorhinostomy in Nepal. Orbit. 24:2:79-82. doi:10.1080/01676830490916073; PMid:16191792

Dasgupta S, Vats V, Varma A (2016). Comparison of external and endoscopic endonasal dacryocystorhinostomy: a hospital based retrospective study. Int J Res Med Sci;4(7):2822-9. doi:10.18203/2320-6012.ijrms20161958

Delaney YM, Khooshabeh R (2002). Fluorescein transit test time and symptomatic outcomes after external dacryocystorhinostomy. Ophthal Plast Reconstr Surg;18(4):281-4. doi:10.1097/00002341-200207000-00009; PMid:12142761

Duwal S, Saiju R (2015). Outcomes of external dacryocystorhinostomy and endoscopic endonasal dacryocystorhinostomy in the management of nasolacrimal duct obstruction. Nepal J Ophthalmol;7(13):39-46. doi:10.3126/nepjoph.v7i1.13165; PMid:26695604

Fayers T, Laverde T, Tay E, Olver JM (2009). Lacrimal surgery success after external dacryocystorhinostomy: functional and anatomical results using strict outcome criteria. Ophthal Plast Reconstr Surg;25(6):473-5. doi:10.1097/ IOP.0b013e3181b81e9f; PMid:19935252

Feretis M, Newton JR, Ram B, Green F (2009). Comparison of external and Endonasal dacryocystorhinostomy. The Journal of Laryngology \& Otology;123(3):315-9. doi:10.1017/S0022215108002685; PMid:18492308

Goel M, Kotwal D, Gupta, D, Sharma M (2016). Comparison of endonasal endoscopic dacryocystorhinostomy over external dacryocystorhinostomy. Int J Med Health Res; 2(12):64-8.

Hartikainen J, Antila J, Varpula M (1998). Prospective randomized comparison of Endonasal endoscopic dacryocystorhinostomy and external dacryocystorhinostomy. Laryngoscope;108: 1861-6. doi:10.1097/00005537199812000-00018; PMid:9851505

Hii BW, McNab AA, Friebel JD (2012). A comparison of external and endonasal dacryocystorhinostomy in regard to patient satisfaction and cost. Orbit;31(2):67-76.

Hurwitz JJ, Rutherford S (1986). Computerized survey of lacrimal surgery patients. Ophthalmology;93(1):14-9. doi:10.1016/S0161-6420(86)33779-5

Jutley G, Karim R, Joharatnam N, Latif S, Lynch G (2013). Patient satisfaction following endoscopic Endonasal dacryocystorhinostomy: a quality of life study. Eye;27:1084-9. doi:10.1038/eye.2013.96; PMid:23846378

Karim R, Ghabrial R, Lynch TF, B Tang (2011) A comparison of external and endoscopic Endonasal dacryocystorhinostomy for acquired nasolacrimal duct obstruction. Clinical Ophthalmology;5:979-89. doi:10.2147/ OPTH.S19455; PMid:21792289.

Limbu B, Lyons HS, Shrestha MK, Tabin GC, Saiju R (2019).Comparison of early versus standard timing for silicone stent removal following External Dacrocystorhinostomy under local anaesthesia. Nepal J Ophthalmol;11(21):24-8. doi: 10.3126/nepjoph.v11i1.254013. 
Moras K, Bhat M, Shreyas CS, Mendonca N, Pinto G (2011). External dacryocystorhinostomy versus endoscopic dacryocystorhinostomy: A comparison. J Clin Diagn Res;5(2):182-6.

Mortimore S, Banhegy GY, Lancaster JL, Karkanevatos A (1999). Endoscopic dacryocystorhinostomy without silicone stenting. Journal of the Royal College of Surgeons of Edinburgh;44(6):371-3.

Rasaily S, Limbu B, Saiju R (2018). External vs. Endonasal Endoscopic Dacryocystorhinostomy: Surgical Success and Patient Satisfaction. Int J Ophthalmic Pathol;7:3. doi: 10.4172/2324-8599.1000225

Robinson K, Gatehouse S, Browning GG (1996). Measuring patient benefit from otorhinolaryngological surgery and therapy. Ann Otol Rhinol Laryngol;105(6):415-22. doi:10.1177/000348949610500601; PMid:8638891

Saiju R, Morse LJ, Weinberg D, Shrestha MK, Ruit S (2009). Prospective randomised comparison of external dacryocystorhinostomy with and without silicone intubation. Br J Ophthalmol;93(9):1220-2. doi:10.1136/ bjo.2008.147819; PMid:19515642

ShamCL,AndrewvanHasseltC(2000). Endoscopicterminaldacryocystorhinostomy. TheLaryngoscope;110(6):1045-9. doi:10.1097/00005537-200006000-00029; PMid:10852528

Sharma BR (2008). Non-endoscopic endonasal dacryocystorhinostomy versus external dacryocystorhinostomy. Kathmandu University Medical Journal;6(4):437-42. doi:10.3126/kumj.v6i4.1731; PMid:19483422

Tarbet KJ, Custer PL (1995). External dacryocystorhinostomy, surgical success, patient satisfaction, and economic cost. Ophthalmology;102(7):1065-70. doi:10.1016/S0161-6420(95)30910-4 